\title{
Differentiation between maxillary and malar midface position within the facial profile
}

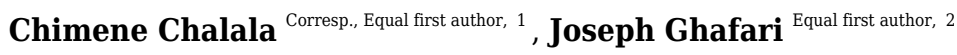 \\ 1 Department of Orthodontics and Dentofacial Orthopedics, Lebanese University and American University of Beirut, Beirut, Lebanon \\ 2 Division of Orthodontics and Dentofacial Orthopedics, American University of Beirut, Beirut, Lebanon \\ Corresponding Author: Chimene Chalala \\ Email address: chalalachimene@yahoo.com
}

Aims: To define midfacial position differentiating maxillary and zygomatic regions and to evaluate the corresponding cephalometric characteristics discerning midfacial flatness and fullness. Material and Methods: One hundred and eighty-three pretreatment lateral cephalometric radiographs of non- growing orthodontic patients(age $25.98 \pm 8.43$ years) screened at our university orthodontic clinic. The lateral cephalographs of the orthodontic patients were stratified in 4groups:flat,normal toward flat, normal toward full, full, according to distances from nasion and sella to points J and G(NJ, SJ, NG, and SG). Jisthe midpoint of the distance connecting orbitale to point $A$, and $G$ the center of the triangle connecting orbit, key ridge and pterygomaxillary fissure. Statistics included the Kendall tau-b test for best associations among measurements. Results: All measurementswere statistically significantly different between flat and full groups. The highest associations were between NJ and SJ ( $\tau b=0.71 ; p<0.001)$ and NG and SG ( $\tau b=$ $0.70 ; p<0.001)$. Flat midfaces were characterized by canting of the cranial base and palatal plane, hyperdivergent pattern and maxillary retrognathism. The opposite was true for fuller midfaces. Conclusion: Midface skeletal location was assessed differentially in the naso-maxillary and malo-zygomatic structures differentially. Craniofacial characteristics were identified according to this stratification, indicating the potential for application in facial diagnosis and need for testing on 3D CBCT images. 
1 Differentiation between maxillary and malar midface position

4

5 Chimène Chalala ${ }^{1}$, Joseph Ghafari ${ }^{2}$

6

$7 \quad{ }^{1}$ Department of Orthodontics and Dentofacial Orthopedics, Lebanese University and American

8 University of Beirut, Beirut, Lebanon.

$9 \quad{ }^{2}$ Division of Orthodontics and Dentofacial Orthopedics, American University of Beirut Medical

10 Center, Beirut, Lebanon.

Corresponding Author:

14 Chimène Chalala ${ }^{1}$

15 Riad El-Solh, Beirut 1107 2020, P.O. Box 11-0236, Beirut, Lebanon.Email address:

16 cc16@aub.edu.lb 


\section{Abstract}

43 Aims: To define midfacial position differentiating maxillary and zygomatic regions and to 44 evaluate the corresponding cephalometric characteristics discerning midfacial flatness and 45 fullness.

46 Material and Methods: One hundred and eighty-three pretreatment lateral cephalometric 47 radiographs of non- growing orthodontic patients (age $25.98 \pm 8.43$ years) screened at our 48 university orthodontic clinic. The lateral cephalographs of the orthodontic patients were stratified 49 in 4 groups: flat, normal toward flat, normal toward full, full, according to distances from nasion 50 and sella to points $\mathrm{J}$ and $\mathrm{G}(\mathrm{NJ}, \mathrm{SJ}, \mathrm{NG}$, and $\mathrm{SG})$. $\mathrm{J}$ is the midpoint of the distance connecting 51 orbitale to point $\mathrm{A}$, and $\mathrm{G}$ the center of the triangle connecting orbit, key ridge and 52 pterygomaxillary fissure. Statistics included the Kendall tau-b test for best associations among 53 measurements.

54 Results: All measurements were statistically significantly different between flat and full 55 groups. The highest associations were between NJ and $\mathrm{SJ}(\tau \mathrm{b}=0.71 ; \mathrm{p}<0.001)$ and $\mathrm{NG}$ and $\mathrm{SG}$ $56(\tau \mathrm{b}=0.70 ; \mathrm{p}<0.001)$. Flat midfaces were characterized by canting of the cranial base and palatal 57 plane, hyperdivergent pattern and maxillary retrognathism. The opposite was true for fuller 58 midfaces.

59 Conclusion: Midface skeletal location was assessed differentially in the naso-maxillary and malo60 zygomatic structures differentially. Craniofacial characteristics were identified according to this 61 stratification, indicating the potential for application in facial diagnosis and need for testing on 3D

63

64

65

66

67 CBCT images.

\section{Introduction}

The location of the midface within the facial profile has been mostly assessed in relation to the maxilla, thus linking maxillary prognathism or retrognathism to associated malocclusions. The position of the maxilla has served as the only practical cephalometric measurement for midface flatness or fullness through the relative position of point A to the cranial base (SNA angle or position of $A$ to nasion perpendicular). ${ }^{1-7}$ Given the restrictive two-dimensional nature of cephalometric analysis, researchers and clinicians focused on this midline landmark (point A) without consideration of the position of the malar bone (cheekbone), which is another essential . . determinant of midfacial flatness or fullness. Indeed, the midface encompasses the region 
73 between the zygoma and maxilla horizontally, and vertically between the eyebrows and subnasale 74 horizontal planes ${ }^{8}$.

75 In planning orthognathic surgery of maxillary retrognathism associated with Class III 76 malocclusion, 2D and 3D simulation programs are based on the movement of the maxilla, with the 77 knowledge that maxillary advancement through the Lefort 1 osteotomy would also lead to fuller 78 cheekbone appearance. ${ }^{9}$ In plastic surgery, midface cheek hollowness has been corrected with the 79 placement of submalar implants addressing the flatness at the zygomatic area. ${ }^{\mathbf{1 0}}$

Most of the research conducted to examine the presence and treatment of dentoskeletal deformities had focused primarily on the lower facial region, ${ }^{\mathbf{1 1 - 1 3}}$ with scarce analyses of midface position as an entity regardless of the type of malocclusion. Singh et al. ${ }^{14}$ evaluated morphometrically the midfacial deficiency in Class III compared with Class I patients through 7 landmarks in the maxilla, but none related to the malar bone. Zide et al. ${ }^{8}$ added orbitale, off the midline, to the regular midline landmarks nasion and A point, to assess midfacial deficiency. Using cone-beam computed tomography (CBCT) derived multiplanar-reconstructed crosssections, Kim et al. ${ }^{15}$ defined differences between male and female soft tissue midface deficiency in Class III malocclusion. We hypothesized that hard tissue differentiation is possible between maxillary and malar positions by identifying representative geometric landmarks within each of these structures corresponding to the different planes in which these structures are located. Key to such identification was to define both the maxillary and malar planes lateral to the midsagittal plane. Given the limitation by Institutional Review Boards in using CBCT imaging as a routine record, we initiated this evaluation on regular 2-D cephlograms as a first step to test this hypothesis.

The aims of this study were to evaluate: 1 - the differential anteroposterior position of the maxillary and zygomatic regions, and the correspondence in diagnosis between these regions, and 2- the corresponding cephalometric characteristics and measurements discerning midfacial flatness and fullness.

\section{Materials \& Methods}

Prior to data collection, the study was approved by [our] university's Institutional Review Board (IRB ID: BIO-2018- 0065). Selected from the database of orthodontic records at [our] Medical Center, the pretreatment lateral cephalometric radiographs of 183 non-growing healthy 
104 patients (mean age $25.98 \pm 8.43$ years; 106 females, 77 males) belonged to patients whose 105 treatment has been initiated or completed. The initial selection criterion was skeletal age, which 106 was determined through the cervical vertebrae maturation (CVM) assessment method as 107 modified by Baccetti et al. ${ }^{16}$ Accordingly, the minimum age for inclusion was 16.2 years for 108 females, and 18.1 years for males.

109 Subjects were excluded from the study if they had a cervical stage $<6$ (because the highest 110 CVM score of 6 indicates cessation of mandibular growth for at least 2 years), previous 111 orthodontic treatment, any craniofacial anomaly (patients with syndromes such as cleft lip/palate, 112 hemifacial macrosomia, Treachers Collins, plagiocephaly, and other congential malformations), 113 or if their radiographs were of non-diagnostic quality.

114 Lateral cephalometric radiographs were taken with the head oriented in natural head position 115 following a standard procedure in the same cephalostat (GE, Instrumentarium, Tuusula, Finland). 116 Selected landmarks were digitized (Fig. 1) and variables measured by one operator (CC) using 117 the View box 4 software (dHAL Software, Kifissia, Greece). The radiographs were calibrated in 118 reference to the ruler present on the lateral cephalograms.

119 To define the separate locations of the maxilla-nasal and malo-zygomatic regions, two 120 geometric landmarks were determined, akin to the geometric definition of point $\mathrm{S}$ for the center 121 of sella turcica (Fig. 1):

122 a. J, the midpoint of the distance connecting points orbitale $(\mathrm{O})$ and $\mathrm{A}$. The rationale for this 123 selection is that flatness or fullness is associated with upper (orbitale) and lower (point A) 125 the maxilla.

b. G, the geometric center of the maxillary triangle described in the Moorrees mesh diagram analysis ${ }^{17}$ and which connects the posterior border of the orbit with the inferior outline of the key ridge (zygomaxillare) and the anterior surface of the pterygomaxillary fissure, which lines up with the malo-zygomatic suture (Fig. 1). By this definition, G is a more lateral landmark that would represent the central malar area.

131 Consequently, $\mathrm{J}$ and $\mathrm{G}$ approximated the positions of the mid-maxillary and malar bones, 132 respectively.

133 Linear measurements were taken of the projections of $\mathrm{J}$ and $\mathrm{G}$ on vertical lines drawn anteriorly 134 through nasion and posteriorly through sella. The measurements were SJ, SG, NJ, and NG 
135 (Fig.1). Given differences in head size among individuals and between genders, these distances 136 were scaled to the cranial base length (SN), and the resulting ratios (SJ/SN x 100, SG/SN x 100, $137 \mathrm{NJ} / \mathrm{SN} \times 100, \mathrm{NG} / \mathrm{SN} \times 100$ ) were calculated. Greater distances between either J or G to the 138 anterior landmark nasion would indicate a tendency toward midface flatness and shorter 139 distances would indicate a direction toward midfacial fullness. The opposite would apply for the 140 distances between either J or $\mathrm{G}$ and the posterior landmark sella. Accordingly, four groups were 141 generated based on the mean and standard deviations of each calculated ratio (Table 1):

142 1- Flat group (f) included the subjects in whom the ratio was less than one standard deviation

143 (SD) for the measurements made relative to the posterior landmark sella and beyond one 144 standard deviation for the measurements calculated relative to the anterior landmark nasion.

145 2- Normal toward flat group (Nf) included the subjects in whom the ratio was between the mean 146 and minus1SD for $\mathrm{J}$ and $\mathrm{G}$ measurements taken relative to sella, and between the mean and plus 147 1SD for measurements calculated relative to nasion.

148 3-Normal toward full group (NF) included the subjects whose ratio was between the mean + 149 1SD for J and G measurements computed to sella, and between the mean + 1SD for the 150 measurements calculated relative to nasion.

151 4-Full group $(F)$ included the subjects whose ratio was beyond +1SD for the measurements 152 calculated to sella and $<1 \mathrm{SD}$ for the measurements computed relative to nasion.

153 Cephalometric measurements of the relationships among cranial base and jaws in the sagittal 154 and vertical planes were compared among these groups. Measurements on all the variables were 155 repeated at different times by the first author on 30 radiographs to assess intra-examiner 156 reliability, and by the second author for inter-rater reproducibility.

158 Statistical analysis

159 The repeated measures were evaluated with the two-way mixed effects intra-class correlations 160 for absolute agreement on single measures. A one-way between subjects analysis of variance 161 (ANOVA) was applied to study differences of selected cephalometric measurements among the 1624 groups. A Kendall's tau-b correlation was employed to determine the relationship between 163 measurements among these groups. The Pearson product-moment correlation was calculated to determine the association among variables, and the intra-class coefficients were calculated for intra and inter examiner reliability. 
As part of post hoc power assessment, effect sizes were calculated for all cephalometric

167

168

169

170

171

172

173

174

175

176

177

178

179

180

181

182

183

184

185

186

187

188

189

190

191

192

193

194

195

196

variables across the 4 groups. For all variables, effect size ranged from 0.543 for ANS-PNS in the $\mathrm{NG}$ comparisons to 2.84 for $\mathrm{SN} / \mathrm{H}$ for the same comparisons (large effect size). Using the total sample size of 183 , the calculated post hoc power ranged between 0.999 and 1.000 for all ANOVA comparisons. However, since this power calculation assumes equal sample sizes, a conservative approach was used to estimate power by using the smallest group sample size and multiplying by 4 , i.e. $\mathrm{n}=96$ for $\mathrm{NJ}$ and $\mathrm{n}=92$ for $\mathrm{NG}$. Using this conservative approach, post hoc sample size varied between 0.995 and 1.000 for all ANOVA comparisons. Accordingly, the sample size was amply sufficient to perform the group comparisons.

The IBM $®$ SPSS $® 23.0$ statistical package was used to carry out all statistical analyses. Statistical significance was set at 0.05 .

\section{Results}

Intra-class correlation coefficients ranged between $0.963<\mathrm{r}<0.996$ for intraexaminer measurements, and $0.924<\mathrm{r}<0.962$ for inter-examiner measurements, indicating high correspondence of the repeated measures and accurate reproducibility of landmark identification. The results are presented in 4 sets of classification based on the 4 defined groups. Under all classifications, the group comparisons revealed statistically significant differences for nearly all the measurements between flat and full groups. The Kendall tau-b test for best associations among the measurements classified on the distances NJ, SJ, NG, and SG over SN (Table 2) revealed the highest associations between measurements assessed by NJ/SN and $\mathrm{SJ} / \mathrm{SN}(\tau b=0.71 ; \mathrm{p}<0.001)$ and those by NG/SN and SG/SN measurements $(\tau b=0.70 ; p<0.001)$. The associations were lower for $\mathrm{SJ} / \mathrm{SN}$ and $\mathrm{NG} / \mathrm{SN}$ measurements $(\tau \mathrm{b}=0.48 ; \mathrm{p}<0.001) ; \mathrm{NJ} / \mathrm{SN}$ and for $\mathrm{SG} / \mathrm{SN}$ measurements $(\tau \mathrm{b}=0.48 ; \mathrm{p}<0.001)$. The concordance $(\%)$ of categorization among groups was not total $(100 \%)$ yet high (79\%-88\%). The discordance ranged between 8 and 22\%, highest between the normal groups (Nf and NF) and nil ( $0 \%$ ) between the extreme groups $\mathrm{F}$ and $\mathrm{f}$. However, when the normal groups were grouped into one group $(\mathrm{N})$, only $5 \%$ to $11 \%$ discordance was observed between $\mathrm{f}$ and $\mathrm{N}$, and between $\mathrm{F}$ and $\mathrm{N}$.

Accordingly, the outcomes defined by $\mathrm{NJ} / \mathrm{SN}$ and NG/SN are displayed for group comparisons (Tables 3,4). The main findings from these comparisons are presented in relation to the cephalometric structures and relations: 
197 198

199

200

201

202

203

204

205

206

207

208

209

210

211

212

213

214

215

216

217

218

219

220

221

222

223

224

225

226

227

228

1-Cranial base: the cant of the cranial base $(\mathrm{SN} / \mathrm{H})$ was statistically significantly greater (lower sella) in the full group relative to the flat group for both the NJ/SN set $(14.70 \pm 4.61 ; 5.64 \pm 3.39$ respectively, Table 3$)$ and the NG/SN set (15.74 $\pm 3.85 ; 5.40 \pm 3.11$ respectively, Table 4).

2- Jaw positions and relations: The SNA angle was smaller in the flat group compared with the full group in both the NJ/SN set (79. $67 \pm 3.85 ; 85.30 \pm 3.79$, respectively, Table 3$)$, and in the NG/SN set $(80.06 \pm 3.76 ; 83.86 \pm 4.34$, respectively, Table 4). No statistically significant difference was observed in the SNB angle among all groups. The ANB angle was statistically significantly smaller in the flat group compared with the full group in both the NJ/SN set ($2.462 \pm 3.5170 ; 4.854 \pm 3.5741$ respectively, Table 3$)$ and the NG/SN set $(-1.519 \pm 3.5846 ; 4.435 \pm$ 3.7640 respectively, Table 4$)$.

3. Jaw-specific measurements: The cant of the palatal plane $(\mathrm{PP} / \mathrm{H})$ was statistically significantly tipped down posteriorly with a fuller midface compared to a flat midface in the NJ/SN set (5.85 $\pm 4.15 ;-2.57 \pm 3.87$ respectively, Table 3$)$, and the NG/SN set $(6.50 \pm 3.60 ;-3.26 \pm 3.22$, respectively, Table 4). As gauged by the maxillary depth (NA/FH) angle, less maxillary depth was observed in flat midfaces. The angle was statistically significantly lower in the flat group compared with the full group in the $\mathrm{NJ} / \mathrm{SN}$ set $(88.58 \pm 3.49 ; 93.68 \pm 3.73$ respectively, Table 3$)$, and the NG/SN set $(88.91 \pm 2.87 ; 93.17 \pm 3.99$ respectively, Table 4$)$.

The mandibular plane was steeper in the flat group, with the mandibular plane angle statistically significantly decreased in the full group relative to the flat group in the NJ/SN set $(14.60 \pm 5.14 ; 22.34 \pm 5.72$ respectively, Table 3$)$, and the NG/SN set $(14.70 \pm 5.92 ; 22.23 \pm$ 4.77 respectively Table 4 ). The upper anterior face height (AFH) was statistically significantly greater in the flat groups (Tables 3,4).

In general, a progression was noted among the statistically significant measurements ascending from the flat group toward the full group.

For the total ungrouped sample, the Pearson correlation coefficients were high between $\mathrm{NJ} / \mathrm{SN}$ and NG/SN $(\mathrm{r}=0.88, \mathrm{p}<0.001)$, and between SJ/SN and SG/SN $(r=0.83, \mathrm{p}<0.001)$.

\section{Discussion}

The findings revealed the potential for differentiating flatness and fullness of the maxillary and the zygomatic areas through distinctive linear measurements made from landmarks defined 
229 within these areas to anterior (nasion) and posterior (sella) cranial base landmarks. This 230 delineation provides a quantitative basis for the assessment of the midface at two levels lateral to 231 the midline, complementing the prevalent method used in practice and prior studies in which the 232 anteroposterior location of the midface was mostly related to the position of the maxilla, ${ }^{1-7}$ often 233 specifically associated with the midsagittal SNA angle. The assessment also supplements 234 methods employed in anthropology, whereby flatness or fullness of the midface has been defined 235 in the frontal plane, mainly by the projection of point A between zygomaxillary anterius right 236 and left points. ${ }^{18,19}$

237 The measurements used to define the groups were different from those used to assess other 238 pertinent characteristic measures. Regardless of the method used for stratifying the 4 groups in 239 gradation from flatness through fullness, the cephalometric measurements revealed the 240 following:

1. flat groups were characterized by a higher position of sella and posteriorly tipped-up palatal plane, features found in Class III malocclusion, which in turn has been associated with maxillary retrognathism and presumed associated midface flatness. ${ }^{20}$ In addition, the midface position was not related to the length of the maxilla as ANS-PNS was similar across all groups. This finding suggests that the position of the maxilla rather than its midsagittal length is associated with midface flatness or fullness. In this context, the subspinale region was in a more backward position in flat groups with less maxillary depth.

2. Steepness of the mandibular plane was more significant in flat groups, portraying a hyperdivergent pattern. The increased mandibular plane angle has been previously reported as the most reliable indicator in assessing facial vertical growth pattern. ${ }^{21}$ The finding that the upper anterior face height was greater in the flat groups may also be related to the association with mandibular hyperdivergence and steepness of the palatal plane.

3. The SNB angle was not statistically significantly different among the groups, indicating that the methods of assessing midface position were typically related to the maxilla and did not discriminate the position of the mandible.

Several findings indicate the suitability of the used measurements to properly reflect midface position: 
260 1. Definite characteristics often clinically associated with either midface flatness or fullness 261 were actually determined with the measurements to $\mathrm{J}$ and $\mathrm{G}$, such as the ANB angle being 262 263

264 265

266

267 268

269

270

271

272

273

274

275

276

277

278

279

280

281

282

283

284

285

286

287

288

289

290

291 smaller in the flat group, as would be expected in a Class III malocclusion, and the opposite holding for increased ANB in the full group, more commensurate with Class II malocclusion. To gauge the applicability of the findings, the methods used in this study were applied in a representative number of patients with variations of midface characteristics. The cephalographs and facial profiles of some of these patients were superimposed and are shown in Fig. 2. Research targeting different malocclusion groups is warranted to further confirm this conclusion.

2. All the statistically different measurements disclosed a progression from flat towards normal and full groups, actually differentiating flat and full midfaces.

3. The correspondence between conclusions based on anterior (NJ/SN and NG/SN) and posterior ( $\mathrm{SJ} / \mathrm{SN}$ and $\mathrm{SG} / \mathrm{SN})$ measurements. Yet, given the higher correlations between $\mathrm{NJ} / \mathrm{SN}$ and $\mathrm{SJ} / \mathrm{SN}$, and between $\mathrm{NG} / \mathrm{SN}$ and $\mathrm{SG} / \mathrm{SN}$ than among any other association (Table 2), using the measurements to nasion would be appropriate, particularly that clinically midface position is assessed to the facial outline.

The findings reflected the potential to measure midfacial traits because of their location, and the possibility of being concordant or discrepant in determining the site of flatness or fullness. However, research is needed to further explore the correspondence between the measurements related to the maxilla and malo-zygomatic complex and panel judgments of midfacial fullness or flatness based on soft tissue profile assessments, notwithstanding the fact that the thickness of the soft tissues may minimize or exaggerate the underlying skeletal relationship. Arnett and Bergman $^{22}$ have established parameters for soft tissue midface analysis based on visual location of landmarks relative to each other, such as the cheekbone point (CP) located on a profile view at a distance of 20 to $25 \mathrm{~mm}$ inferior and 5 to $10 \mathrm{~mm}$ anterior to the outer canthus (OC) of the eye. Seemingly, the authors represent a bony structure by its soft tissue correspondence within a range of $5 \mathrm{~mm}$ from a landmark located at another anteroposterior plane.

The selection of landmarks to define midface position was based on the components of the midface: the naso-maxillary complex and the malo-zygomatic complex. Point J, located in the medial-central maxilla, also reflects the position of the adjacent nose, the central feature of the face. Point G represents the more lateral malo-zygomatic unit. Both landmarks are virtual 
292 geometric points that represent the center of the anterior maxilla $(\mathrm{J})$, and the centroid of the 293 malozygomatic triangle (G). The potential for a "center point" to be used as a proxy to identify 294 the location of the maxilla and cheekbone is common in cephalometrics, including the location 295 of sella turcica, symphyseal point $\mathrm{D},{ }^{2} \mathrm{Xi}$ point, ${ }^{6,7}$ and the center of the orbit. ${ }^{23}$ However, $\mathrm{J}$ and $\mathrm{G}$ 296 are derived from readily definable anatomical structures used in various cephalometric analyses 297 (the pterygoid plate ${ }^{7}$, the orbit ${ }^{23}$, the key ridge ${ }^{17}$, and point $\mathrm{A}^{2,3}$ ) with reproducible identification, 298 as also demonstrated with the high intraclass correlation coefficients between the repeated intra299 and inter- examiner identifications.

300 The locations of the maxillary and malo-zygomatic structures and corresponding 301 "centroids" are not uniplanar in the frontal geometry of the face, similar to common practices in 302 cephalometrics, in which midline structures are evaluated in the midsagittal plane (SN, SNA, 303 SNB, ANB) and bilateral structures are assessed in other planes (Frankfort horizontal, Co-Go, 304 etc,). In all such instances, the cephalometric measurement is referenced to anatomy, itself 305 necessarily multiplanar. The "multiplane analysis" was also described to define various levels of 306 the multilayered face on the $2 \mathrm{D}$ posteroanterior cephalograph. ${ }^{24,25}$ Underscoring the significance 307 of multiplanar analyses, $\mathrm{J}$ and $\mathrm{G}$ also provided the definition of multisagittal planes.

308 Testing on 3D CBCT images should facilitate the study of midface position and provide 309 more accurate measurements than the present 2D assessments. The use of CBCT imaging has not 310 become and is not recommended as the routine cephalometric record in daily orthodontic 311 practice because of radiation doses. ${ }^{26} \mathrm{~A}$ recent study employing 3D CBCT images included both 312 the maxillary and malar areas in the assessment of midface deficiency through 3D CBCT 313 images. ${ }^{15}$ Although the approach was based on the definition of intersecting horizontal and 314 vertical planes through specific landmarks on the orbit and the zygomaticomaxillary suture, this 315 approach did not yield guidelines for routine application in individual patients. The exploration 316 of our method in 3D CBCT images should determine this possibility. Furthermore, the application 317 of shape analysis employed in cephalometric imaging ${ }^{27}$ (e.g. tensor biometrics, finite element 318 analysis, Procrustes method) and that could forego limitations of conventional cephalometric 319 measurements might yield proportional assessments of the midface in its location within the face.

320 Nevertheless, it is remarkable that differences presumably in frontal planes could be depicted on 321 a 2D sagittal cephalograph, allowing the differentiation, at levels other than the midsagittal 322 plane, between maxillary and malar midface position. Although the findings suggested high 
323 correlations between midface location at the maxilla and the malar bone, variations between

324

325

326

327

328

329

330

331

332

333

334

335

336

337

338

339

340

341

342

343

344

345

346

347

348

349

350

351

352

353

these areas, along with the implications of multiplanar midface measurements on facial esthetics, treatment of malocclusion, and outcome of maxillary orthognathic surgery should be investigated.

In addition, longitudinal assessment of midface position throughout growth is needed, particularly in the context of increased or decreased flatness relative to mandibular growth. Indeed, the ANB angle decreases with growth ${ }^{28}$ and it is possible that midface flatness might increase with such development, notwithstanding its probable increase in Class III malocclusions. Also, given the importance of proportional assessment of facial structures relative to each other, whereby absolute measurements are interpreted in the context of those of adjacent structures, ${ }^{17}$ future studies should be focused on the proportionality of the midface maxillary and malar positions relative to forehead and mandible. Gender differences should also be further delineated.

\section{Conclusions}

1. The findings indicated that skeletal location of the naso-maxillary and malo-zygomatic structures can be assessed differentially. In most individuals, the locations are diagnostically similar.

2. Because the distances between either points ( $\mathrm{J}$ or $\mathrm{G}$ ) and other reference landmarks (nasion and sella) differ without reflecting their proportionality to head size and gender variations, the distances involving these landmarks were scaled to the cranial base length (SN) for statistical computation.

3. Measurements from nasion and sella to the maxillary and malar landmarks yielded similar findings. Accordingly, the anterior distances to nasion were adopted, reflecting the routine clinical assessment relative to the facial profile.

4. Stratification of midface position in gradation through 4 groups from flat to full allowed for corresponding depiction of facial measurements. Flat midfaces were characterized by canting of the cranial base and palatal plane, hyperdivergent pattern and a backward position of the maxilla (maxillary hypoplasia). The opposite was true for fuller midfaces.

5. Research is warranted in to explore midface location in relation to different variables (types of malocclusion, growing individuals, other facial structures such as forehead and mandible). 
354

355

356

357

358

359

360

361

362

363

364

365

366

367

368

369

370

371

372

373

374

375

376

377

378

379

380

381

382

383

384

385

386

387

388

389

390

391

392

393

394

395

396

397
Also, 3D imaging should help evaluate relationships between hard and soft tissue for proper differential diagnosis, along with the associations with facial esthetics and treatment of malocclusion.

\section{References}

1- McNeill RW, Proffit WR, White RP. Cephalometric prediction for orthodontic surgery. Angle Orthod 1972;42:154-64.

2- Steiner C. Cephalometrics for you and me. Am J Orthod. 1953;39:729-55.

3- Downs WB. Variations in facial relationship: their significance in treatment and prognosis. Angle Orthod. 1949;19:145-155.

4- McNamara JA. A method of cephalometric evaluation. Ann Arbor. 1984; 86:449-69.

5- Jarabak JR, Fizzel JA. Technique and treatment with light wire edgewise appliances. (2nd. ed.), St. Louis: Mosby; 1972.

6- Ricketts RM. A foundation for cephalometric communication. Am J Orthod. 1960;46:33057.

7- Ricketts RM. Cephalometric analysis and synthesis. Angle Orthod. 1961;31:141-56.

8- Zide B, Grayson B, McCarthy JG. Cephalometric analysis for upper and lower midface surgery: Part II. Plast Reconstr Surg 1981;68:961-8.

9- Petersen C, Markiewicz MR, Miloro M. Is augmentation required to correct malar deficiency with maxillary advancement? J Oral Maxillofac Surg. 2018;76:1283-90.

10- Kridel, R.W.H., Patel, S. Cheek and Chin Implants to Enhance Facelift Results. Facial Plastic Surgery 2017;33:279-84.

11- Brooks BW1, Buschang PH, Bates JD, Adams TB, English JD. Predicting upper lip response to 4-piece maxillary LeFort I osteotomy. Am J Orthod Dentofacial Orthop. 2001 ;120(2):12433.

12- Kolokitha OE, Topouzelis N. Cephalometric methods of prediction in orthognathic surgery. J Maxillofac Oral Surg. 2011; 10(3): 236-245.

13- Betts NJ, Vig KW, Vig P, Spalding P, Fonseca RJ. Changes in the nasal and labial soft tissues after surgical repositioning of the maxilla. Int J Adult Orthodon Orthognath Surg. 1993;8:723. 
398

399

400

401

402

403

404

405

406

407

408

409

410

411

412

413

414

415

416

417

418

419

420

421

422

423

424

425

426

427

428

429

430

431

432

433

434

435

436

437

438

439

440

441

442

443

14- Singh GD, McNamara JA Jr, Lozanoff S. Morphometry of the midfacial complex in subjects with class III malocclusions: Procrustes, Euclidean, and cephalometric analyses. Clin Anat 1998; 11:162-70.

15- Kim B, Lee HC, Kim SH, Kim Y, Son W, Kim SS. Hard- and soft-tissue profiles of the midface region in patients with skeletal Class III malocclusion using cone-beam computed tomography multiplanar reconstructed image analysis. Korean J Orthod. 2018; 48:143-52.

16- Baccetti T, Franchi L, McNamara JA Jr. The Cervical vertebral maturation (CVM) method for the assessment of optimal treatment timing in dentofacial orthopedics. Semin Orthod. 2005; 11:119-29.

17- Ghafari, JG. The Moorrees mesh diagram: proportionate analysis of the human face. In: Radiographic Cephalometry- From Basics to 3-D Imaging Second edition. A. Jacobson and R.L. Jacobson (editors). Chicago: Quintessence Publishing Co. 2006:161-84.

18- Yamaguchi B. Facial flatness measurements of the Ainu and Japanese crania. Bull Natl Sci Mus. 1973; 16:161-171.

19- Yamaguchi B. A study on the facial flatness of the Jomon crania. Bull Natl Sci Mus Tokyo. $1980 ; 6: 21-28$.

20- Ghafari JG, Haddad RV, Saadeh ME. Class III malocclusion: the evidence on diagnosis and treatment. In: Evidence-based orthodontics. G. Huang, K. Vig (editors). Wiley-Blackwell Publishing Ltd. Ch. 16: 247-280, 2011.

21-Ahmed M, Shaikh A, Fida M. Diagnostic performance of various cephalometric parameters for the assessment of vertical growth pattern. Dental Press J Orthod. 2016; 21(4):41-9.

22- Arnett WG, Bergman RT. Facial keys to orthodontic diagnosis and treatment planning - part II. Am J Orthod Dentofacial Orthop. 1993; 103(5):395-41.

23- Huertas D, Ghafari, J. New posteroanterior cephalometric norms: A comparison with craniofacial measures of children treated with palatal expansion. Angle Orthod. 2001; 71: 285-92.

24- Ghafari GJ. Posteroanterior cephalometry: craniofacial frontal analysis. In: Radiographic Cephalometry- From Basics to 3-D Imaging Second edition. A. Jacobson and R.L. Jacobson, editors. Chicago: Quintessence Publishing Co. 267-292, 2006.

25- Grayson BH, McCarthy JG, Bookstein F. Analysis of craniofacial asymmetry by multiplane cephalometry. Am J Orthod. 1983 Sep; 84(3):217-224.

26- American Academy of Oral and Maxillofacial Radiology. Clinical recommendations regarding use of cone beam computed tomography in orthodontics. Position statement by the

Peer) reviewing PDF | (2019:08:40500:1:1:NEW 8 Nov 2019) 
444 American Academy of Oral and Maxillofacial Radiology. Oral Surg Oral Med Oral Pathol $445 \quad$ Oral Radiol. 2013; 116:238-57.

446

447 27- Bookstein FL. Reconsidering "The inappropriateness of conventional cephalometrics". Am J 448 Orthod Dentofacial Orthop. 2016 Jun; 149(6):784-97.

449

450 28-Van Diepenbeek AF, Buschang PH, Prahl-Andersen B. Age-dependant cephalometric 451 standards as determined by multilevel modeling. Am J Orthod Dentofacial Orthop. 2009 452 Jan;135(1):79-87.

453

454

455

456

457 


\section{Table 1 (on next page)}

Distribution of 4 groups according to the position of $\mathrm{J}$ and $\mathrm{G}$ relative to nasion and sella 
1

Table 1: Distribution of 4 groups according to the position of $J$ and $G$ relative to nasion and sella

\begin{tabular}{|c|c|c|c|c|}
\hline $\begin{array}{c}\text { Measurement } \\
\text { Mean-SD }\end{array}$ & Flat & Normal toward flat & Normal toward Full & Full \\
\hline $\begin{array}{c}\text { SJ/SN x 100 } \\
91.46 \pm 4.81\end{array}$ & $\begin{array}{c}<6.65 \\
(n=35)\end{array}$ & $\begin{array}{c}86.65-91.46 \\
(n=52)\end{array}$ & $\begin{array}{c}91.46-96.27 \\
(n=69)\end{array}$ & $\begin{array}{c}>96.27 \\
(n=27)\end{array}$ \\
\hline $\mathrm{SG} / \mathrm{SN} \times 100$ & $<50.2$ & $50.2-53.45$ & $53.45-56.7$ & $>56.7$ \\
$53.45 \pm 3.25$ & $(n=29)$ & $(n=64)$ & $(n=62)$ & $(n=28)$ \\
\hline $\mathrm{NJ} / \mathrm{SN} \times 100$ & $>12.09$ & $6.41-12.09$ & $0.73-6.41$ & $<0.73$ \\
$6.41 \pm 5.68$ & $(n=29)$ & $(n=60)$ & $(n=70)$ & $(n=24)$ \\
\hline NG/SNx 100 & $>48.59$ & $44.41-48.59$ & $40.23-44.41$ & $<40.23$ \\
$44.41 \pm 4.18$ & $(n=26)$ & $(n=60)$ & $(n=74)$ & $(n=23)$ \\
\hline
\end{tabular}

3 


\section{Table 2 (on next page)}

Kendall's tau-b test

Kendall's tau-b among cephalometric measurements* and concordance percentage (\%) among defined categories 
1

2

3

4

5

6

Table 2: Kendall's tau-b among cephalometric measurements* and concordance percentage (\%) among defined categories

\begin{tabular}{|c|c|c|c|}
\hline & NJ/SN & NG/SN & SJ/SN \\
\hline NJ/SN & & & \\
\hline NG/SN & $0.687(88 \%)$ & & \\
\hline SJ/SN & $0.712(87 \%)$ & $0.482(78 \%)$ & \\
\hline SG/SN & $0.481(78 \%)$ & $0.701(87 \%)$ & $0.53(79 \%)$ \\
\hline
\end{tabular}

*based on group classifications ( $f, N f, N F, F)$ according to the distances from $\mathrm{J}$ and $\mathrm{G}$ to nasion (N) and sella (S) 


\section{Table 3(on next page)}

Comparison of measurements among groups as defined by NJ/SNx100 ( $n=183)$ 
Table 3: Comparison of measurements among groups as defined by $\mathrm{NJ} / \mathrm{SNx} 100$ $(n=183)$

\begin{tabular}{|c|c|c|c|c|c|c|c|c|c|c|}
\hline \multicolumn{11}{|c|}{ A- Analysis of Variance (ANOVA test) } \\
\hline & \multicolumn{2}{|c|}{ Flat } & \multicolumn{2}{|c|}{$\begin{array}{c}\text { Normal to } \\
\text { Flat }\end{array}$} & \multicolumn{2}{|c|}{ Normal to Full } & \multicolumn{2}{|c|}{ Full } & \multicolumn{2}{|c|}{ ANOVA } \\
\hline $\mathrm{NJ} / \mathrm{SN} \times 100$ & \multicolumn{2}{|c|}{$>12.09$} & \multicolumn{2}{|c|}{$6.41-12.09$} & \multicolumn{2}{|c|}{$0.73-6.41$} & \multicolumn{2}{|c|}{$<0.73$} & & \\
\hline \multirow[t]{2}{*}{$\mathrm{n}$} & \multicolumn{2}{|c|}{29} & \multicolumn{2}{|c|}{60} & \multicolumn{2}{|c|}{70} & \multicolumn{2}{|c|}{24} & & \\
\hline & Mean & SD & Mean & SD & Mean & SD & Mean & SD & $\mathrm{F}$ & $p$ \\
\hline \multicolumn{11}{|c|}{ Sagittal measurements } \\
\hline $\mathrm{SN} / \mathrm{H}$ & 5.64 & 3.39 & 10.59 & 3.90 & 11.88 & 3.85 & 14.70 & $\begin{array}{c}4.60 \\
5\end{array}$ & $\begin{array}{c}26.6 \\
4\end{array}$ & $<0.001^{*}$ \\
\hline SNA & 79.67 & 3.85 & 80.51 & 4.54 & 83.30 & 3.44 & 85.30 & $\begin{array}{c}3.79 \\
4\end{array}$ & $\begin{array}{c}14.3 \\
9\end{array}$ & $<0.001^{*}$ \\
\hline SNB & 82.10 & 4.59 & 78.88 & 5.01 & 79.30 & 4.09 & 80.44 & $\begin{array}{c}5.17 \\
3\end{array}$ & 3.59 & $0.015^{\star}$ \\
\hline ANB & -2.46 & 3.52 & 1.62 & 3.96 & 4.00 & 3.29 & 4.85 & $\begin{array}{c}3.57 \\
4\end{array}$ & $\begin{array}{c}26.9 \\
5\end{array}$ & $<0.001^{*}$ \\
\hline $\begin{array}{l}\text { Maxillary } \\
\text { depth }\end{array}$ & 88.58 & 3.49 & 89.86 & 3.59 & 92.52 & 3.02 & 93.68 & $\begin{array}{c}3.72 \\
8\end{array}$ & $\begin{array}{c}16.7 \\
8\end{array}$ & $<0.001^{*}$ \\
\hline ANS-PNS & 54.31 & 3.69 & 52.41 & 4.00 & 53.25 & 4.25 & 53.56 & $\begin{array}{c}4.36 \\
9\end{array}$ & 1.51 & 0.214 \\
\hline \multicolumn{11}{|c|}{ Vertical measurements } \\
\hline $\mathrm{PP} / \mathrm{H}$ & -2.57 & 3.87 & 1.72 & 4.11 & 2.87 & 3.69 & 5.85 & 4.15 & $\begin{array}{c}22.1 \\
3\end{array}$ & $<0.001^{*}$ \\
\hline $\mathrm{MP} / \mathrm{H}$ & 22.34 & 5.72 & 19.72 & 6.32 & 19.88 & 5.73 & 14.60 & $\begin{array}{c}5.13 \\
6 \\
\end{array}$ & 8.01 & $\underset{*}{<0.001^{*}}$ \\
\hline $\mathrm{PP} / \mathrm{MP}$ & 19.79 & 7.01 & 21.45 & 7.01 & 22.754 & 6.57 & 20.44 & 6.40 & 1.62 & 0.187 \\
\hline SN/MP & 28.01 & 7.13 & 30.31 & 7.52 & 31.753 & 6.63 & 29.29 & 6.59 & 2.20 & 0.090 \\
\hline Upper AFH & 52.84 & 2.73 & 51.82 & 3.14 & 51.30 & 3.37 & 50.42 & 2.95 & 2.92 & $0.036^{*}$ \\
\hline Lower AFH & 66.58 & 7.57 & 64.42 & 7.40 & 64.65 & 6.85 & 63.76 & 5.91 & $\begin{array}{c}0.85 \\
9\end{array}$ & 0.464 \\
\hline Total AFH & $\begin{array}{c}119.4 \\
2 \\
\end{array}$ & 8.82 & $\begin{array}{c}116.2 \\
2 \\
\end{array}$ & 8.43 & 115.95 & 8.26 & $\begin{array}{c}114.1 \\
8 \\
\end{array}$ & 6.65 & 1.96 & 0.12 \\
\hline UAFH/TAFH & 44.38 & 2.70 & 44.70 & 2.96 & 44.34 & 2.76 & 44.23 & 2.70 & 0.25 & 0.86 \\
\hline $\mathrm{LAFH} / \mathrm{TAFH}$ & 55.62 & 2.70 & 55.30 & 2.96 & 55.65 & 2.76 & 55.77 & 2.70 & 0.25 & 0.86 \\
\hline UAFH/LAFH & 80.23 & 8.88 & 81.37 & 9.85 & 80.09 & 8.96 & 79.72 & 8.68 & 0.29 & 0.83 \\
\hline
\end{tabular}
5

H- horizontal; maxillary depth: angle between Frankfort horizontal and NA; AFH: anterior face height

\begin{tabular}{|l|c|c|c|c|c|c|c|}
\hline \multicolumn{7}{|c|}{ B- Post hoc comparisons of statistically significant measurements by ANOVA } \\
\hline & $\begin{array}{c}\text { ANOVA } \\
p\end{array}$ & $\begin{array}{c}\text { Flat vs. } \\
\text { Normal } \\
\text { flat }\end{array}$ & $\begin{array}{c}\text { Flat vs. } \\
\text { Normal } \\
\text { full }\end{array}$ & $\begin{array}{c}\text { Flat } \\
\text { vs. Full }\end{array}$ & $\begin{array}{c}\text { Normal flat } \\
\text { vs. Normal } \\
\text { full }\end{array}$ & $\begin{array}{c}\text { Normal } \\
\text { flat } \\
\text { vs. Full }\end{array}$ & $\begin{array}{c}\text { Normal } \\
\text { full } \\
\text { vs. Full }\end{array}$ \\
\hline SN/H & $\begin{array}{c}<0.001^{*} \\
{ }^{*}\end{array}$ & $<0.001^{* *}$ & $<0.001^{* *}$ & $<0.001^{* *}$ & 0.379 & $<0.001^{* *}$ & $0.016^{*}$ \\
\hline SNA & $\begin{array}{c}<0.001^{*} \\
{ }^{*}\end{array}$ & 1.000 & $<0.001^{* *}$ & $<0.001^{* *}$ & $0.001^{* *}$ & $<0.001^{* *}$ & 0.192 \\
\hline SNB & $0.015^{*}$ & $0.015^{*}$ & $0.040^{*}$ & 1.000 & 1.000 & 1.000 & 1.000 \\
\hline ANB & $\begin{array}{c}<0.001^{*} \\
\text { Maxillary } \\
\text { depth }\end{array}$ & $<0.001^{* *}$ & $<0.001^{* *}$ & $<0.001^{* *}$ & $0.001^{* *}$ & $0.002^{* *}$ & 1.000 \\
\hline
\end{tabular}




\begin{tabular}{|l|c|c|c|c|c|c|c|}
\hline $\mathrm{PP} / \mathrm{H}$ & $\begin{array}{c}<0.001^{*} \\
*\end{array}$ & $<0.001^{* *}$ & $<0.001^{* *}$ & $<0.001^{* *}$ & 0.574 & $<0.001^{* *}$ & $0.009^{* *}$ \\
\hline $\mathrm{MP} / \mathrm{H}$ & $\begin{array}{c}<_{*}^{*} 001^{*} \\
\mathrm{UAFH}\end{array}$ & 0.298 & 0.355 & $<0.001^{* *}$ & 1.000 & $0.002^{* *}$ & $0.001^{* *}$ \\
\hline
\end{tabular}

$7 \quad{ }^{*}$ Statistically significant at $p<0.05 ;{ }^{* *}$ Statistically significant at $p<0.01$ 
Table 4 (on next page)

Comparison of measurements among groups as defined by NG/SNx100 $(n=183)$ 
3

Table 4: Comparison of measurements among groups as defined by NG/SNx100 $(n=183)$

\begin{tabular}{|c|c|c|c|c|c|c|c|c|c|c|}
\hline \multicolumn{11}{|c|}{ A- Analysis of Variance (ANOVA test) } \\
\hline & \multicolumn{2}{|c|}{ Flat } & \multicolumn{2}{|c|}{ Normal to Flat } & \multicolumn{2}{|c|}{ Normal to Full } & \multicolumn{2}{|c|}{ Full } & \multicolumn{2}{|c|}{ ANOVA } \\
\hline NG/SN x100 & \multicolumn{2}{|c|}{$>48.59$} & \multicolumn{2}{|c|}{$44.41-48.59$} & \multicolumn{2}{|c|}{$40.23-44.41$} & \multicolumn{2}{|c|}{$<40.23$} & \\
\hline $\mathrm{n}$ & \multicolumn{2}{|c|}{26} & \multicolumn{2}{|c|}{60} & \multicolumn{2}{|c|}{74} & \multicolumn{2}{|c|}{23} & & \\
\hline & Mean & SD & Mean & SD & Mean & SD & Mean & SD & $\mathrm{F}$ & $p$ \\
\hline \multicolumn{11}{|c|}{ Sagittal measurements } \\
\hline $\mathrm{SN} / \mathrm{H}$ & 5.396 & $\begin{array}{c}3.11 \\
2\end{array}$ & 9.872 & $\begin{array}{c}3.76 \\
9\end{array}$ & $\begin{array}{c}12.01 \\
2\end{array}$ & 3.82 & 15.735 & $\begin{array}{c}3.85 \\
4\end{array}$ & $\begin{array}{c}35.71 \\
5\end{array}$ & $\begin{array}{c}<0.001^{*} \\
*\end{array}$ \\
\hline SNA & $\begin{array}{c}80.05 \\
8\end{array}$ & $\begin{array}{c}3.75 \\
9\end{array}$ & $\begin{array}{c}81.68 \\
7\end{array}$ & $\begin{array}{c}4.67 \\
4\end{array}$ & $\begin{array}{c}82.52 \\
3\end{array}$ & 4.03 & 83.861 & 4.34 & 3.734 & $0.012^{*}$ \\
\hline SNB & $\begin{array}{c}81.55 \\
0 \\
\end{array}$ & $\begin{array}{c}4.82 \\
1 \\
\end{array}$ & $\begin{array}{c}79.18 \\
7 \\
\end{array}$ & $\begin{array}{c}5.04 \\
6 \\
\end{array}$ & $\begin{array}{c}79.69 \\
2 \\
\end{array}$ & 4.06 & 79.417 & $\begin{array}{c}5.56 \\
2 \\
\end{array}$ & 1.595 & 0.192 \\
\hline ANB & -1.519 & $\begin{array}{c}3.58 \\
5\end{array}$ & 2.500 & $\begin{array}{c}4.47 \\
1\end{array}$ & 2.835 & 3.77 & 4.435 & $\begin{array}{c}3.76 \\
4\end{array}$ & $\begin{array}{c}10.63 \\
3\end{array}$ & $\begin{array}{c}<0.001^{*} \\
*\end{array}$ \\
\hline $\begin{array}{l}\text { Maxillary } \\
\text { depth }\end{array}$ & $\begin{array}{c}88.91 \\
2\end{array}$ & $\begin{array}{c}2.87 \\
3\end{array}$ & $\begin{array}{c}90.70 \\
0\end{array}$ & $\begin{array}{c}3.68 \\
2\end{array}$ & $\begin{array}{c}91.73 \\
8\end{array}$ & $\begin{array}{c}3.72 \\
3\end{array}$ & 93.165 & 3.99 & 6.583 & $\begin{array}{c}<0.001^{*} \\
*\end{array}$ \\
\hline ANS-PNS & $\begin{array}{c}53.99 \\
2 \\
\end{array}$ & $\begin{array}{c}2.74 \\
4\end{array}$ & $\begin{array}{c}53.63 \\
5 \\
\end{array}$ & $\begin{array}{c}4.34 \\
4\end{array}$ & $\begin{array}{c}52.71 \\
1 \\
\end{array}$ & $\begin{array}{c}4.18 \\
2 \\
\end{array}$ & 52.587 & 4.54 & 1.062 & 0.367 \\
\hline \multicolumn{11}{|c|}{ Vertical measurements } \\
\hline $\mathrm{PP} / \mathrm{H}$ & -3.262 & $\begin{array}{c}3.21 \\
6\end{array}$ & 1.417 & $\begin{array}{c}4.33 \\
1\end{array}$ & 2.974 & $\begin{array}{c}3.39 \\
9\end{array}$ & 6.500 & $\begin{array}{c}3.59 \\
9\end{array}$ & $\begin{array}{c}30.53 \\
5\end{array}$ & $<0.001^{*}$ \\
\hline $\mathrm{MP} / \mathrm{H}$ & $\begin{array}{c}22.22 \\
7\end{array}$ & $\begin{array}{c}4.76 \\
8\end{array}$ & $\begin{array}{c}20.37 \\
2\end{array}$ & $\begin{array}{c}5.61 \\
8\end{array}$ & $\begin{array}{c}19.39 \\
5\end{array}$ & $\begin{array}{c}6.40 \\
9\end{array}$ & 14.700 & $\begin{array}{c}5.92 \\
4\end{array}$ & 7.404 & $\underset{*}{<0.001^{*}}$ \\
\hline PP/MP & $\begin{array}{c}18.98 \\
8 \\
\end{array}$ & $\begin{array}{c}5.62 \\
2 \\
\end{array}$ & $\begin{array}{c}21.80 \\
3 \\
\end{array}$ & $\begin{array}{c}6.81 \\
4 \\
\end{array}$ & $\begin{array}{c}22.36 \\
1 \\
\end{array}$ & 6.9 & 21.191 & $\begin{array}{c}7.32 \\
6 \\
\end{array}$ & 1.648 & 0.180 \\
\hline SN/MP & $\begin{array}{c}27.63 \\
8\end{array}$ & 5.54 & $\begin{array}{c}30.24 \\
8\end{array}$ & $\begin{array}{c}7.02 \\
1 \\
\end{array}$ & $\begin{array}{c}31.39 \\
2\end{array}$ & $\begin{array}{c}7.24 \\
1 \\
\end{array}$ & 30.435 & $\begin{array}{c}7.79 \\
8 \\
\end{array}$ & 1.837 & 0.142 \\
\hline Upper AFH & 52.75 & 2.53 & 51.96 & 3.13 & 51.37 & 3.35 & 50.07 & 3.04 & 3.378 & $0.020^{*}$ \\
\hline Lower AFH & 64.01 & 6.68 & 64.56 & 7.29 & 65.50 & 7.20 & 63.76 & 6.31 & 0.537 & 0.658 \\
\hline Total AFH & $\begin{array}{c}116.7 \\
5\end{array}$ & 7.89 & $\begin{array}{c}116.5 \\
2\end{array}$ & 7.91 & $\begin{array}{c}116.8 \\
6\end{array}$ & 9.01 & 113.83 & 7.26 & 0.828 & 0.480 \\
\hline UAFH/TAFH & 45.29 & 2.47 & 44.72 & 3.14 & 44.06 & 2.55 & 44.07 & 2.76 & 1.617 & 0.187 \\
\hline LAFH/TAFH & 54.71 & 2.47 & 55.28 & 3.15 & 55.94 & 2.55 & 55.91 & 2.77 & 1.592 & 0.193 \\
\hline UAFH/LAFH & 83.15 & 8.45 & 81.49 & $\begin{array}{c}10.4 \\
2\end{array}$ & 79.12 & 8.21 & 79.23 & 8.89 & 1.678 & 0.173 \\
\hline
\end{tabular}

\begin{tabular}{|l|c|c|c|c|c|c|c|}
\hline \multicolumn{7}{|c|}{ B- Post hoc comparisons of statistically significant measurements by ANOVA } \\
\hline & ANOVA $p$ & $\begin{array}{c}\text { Flat vs. } \\
\text { Normal } \\
\text { flat }\end{array}$ & $\begin{array}{c}\text { Flat vs. } \\
\text { Normal full }\end{array}$ & $\begin{array}{c}\text { Flat } \\
\text { vs. Full }\end{array}$ & $\begin{array}{c}\text { Normal flat } \\
\text { vs. Normal } \\
\text { full }\end{array}$ & $\begin{array}{c}\text { Normal } \\
\text { flat } \\
\text { vs. Full }\end{array}$ & $\begin{array}{c}\text { Normal full } \\
\text { vs. Full }\end{array}$ \\
\hline SN/H & $<0.001^{* *}$ & $<0.001^{* *}$ & $<0.001^{* *}$ & $<0.001^{* *}$ & $0.007^{* *}$ & $<0.001^{* *}$ & $<0.001^{* *}$ \\
\hline SNA & $0.012^{*}$ & 0.630 & 0.072 & $0.013^{*}$ & 1.000 & 0.232 & 1.000 \\
\hline ANB & $<0.001^{* *}$ & $<0.001^{* *}$ & $<0.001^{* *}$ & $<0.001^{* *}$ & 1.000 & 0.297 & 0.569 \\
\hline $\begin{array}{c}\text { Maxillary } \\
\text { depth }\end{array}$ & $<0.001^{* *}$ & 0.226 & $0.005^{* *}$ & $<0.001^{* *}$ & 0.614 & 0.038 & 0.612 \\
\hline PP/H & $<0.001^{* *}$ & $<0.001^{* *}$ & $<0.001^{* *}$ & $<0.001^{* *}$ & 0.104 & $<0.001^{* *}$ & $0.001^{* *}$ \\
\hline
\end{tabular}




\begin{tabular}{|c|c|c|c|c|c|c|c|}
\hline $\mathrm{MP} / \mathrm{H}$ & $<0.001^{* *}$ & 1.000 & 0.217 & $<0.001^{* *}$ & 1.000 & $0.001^{* *}$ & $0.006^{* *}$ \\
\hline $\mathrm{UAFH}$ & $0.020^{*}$ & 1.000 & 0.333 & 0.020 & 1.000 & 0.090 & 0.512 \\
\hline
\end{tabular}

${ }^{*}$ Statistically significant at $p<0.05 ;{ }^{* *}$ Statistically significant at $p<0.01$

7 


\section{Figure 1}

Cephalometric landmarks and measurements, with 2 new landmarks defining midfacial flatness

A: Cephalometric landmarks and measurements, with 2 new landmarks defining midfacial flatness: J, the midpoint of the distance connecting orbitale to point $A$, and $G$, the center of maxillary triangle: $a$ : the dorsal surface of the orbit in the infratemporal fossa, $b$ : the deepest point on the curved anterior surface of the pterygomaxillary fissure, c: the lowest point on the outline of the zygomatic process. Vertical: corresponds to natural head position.

Landmarks: N: nasion; S: sella; Go: gonion; Gn: gnathion; B: B point; A: A point; ANS: anterior nasal spine; PNS: posterior nasal spine; Or: orbitale; Po: porion; J: midpoint of the distance connecting orbitale point to A point; G: center of maxillary triangle; a: posterior border of the orbit; $b$ : deepest point of the anterior curvature of pterigomaxillary fissure; $c$ : lowest point of the key ridge. Measurements: SN: anterior cranial base; PP: palatal plane; ANS-PNS; MP: mandibular plane; Go-Gn. Angles : SN to Horizontal (H); PP to Horizontal $(\mathrm{H})$; MP to Horizontal (H); SNA; SNB; ANB; SN-MP; Maxillary depth: angle between Frankfort plane and NA line. Linear flatness measurements : S-J; N-J; S-G; N-G, all taken between the projections of J and $G$ on the vertical lines through nasion and sella. B,C: Graphs illustrating on sagittal (B) and frontal (C) views the virtual geometric positions of: a. point J (in yellow), nearly in the center of the naso-maxillary complex in the transverse plane and midway between orbit and palatal plane in the vertical dimension, essentially capturing the position of the maxilla in the midface, and b. point $G$ (in red), nearly in the center of the malozygomatic complex between the posterior wall of the orbit, the pteyrygomaxillary plate and the key ridge, essentially defined by the lateral boundaries of the maxilla and representing the cheekbone projection in the midface. The horizontal lines indicate the correspondence of landmarks between the lateral and frontal skull views. 


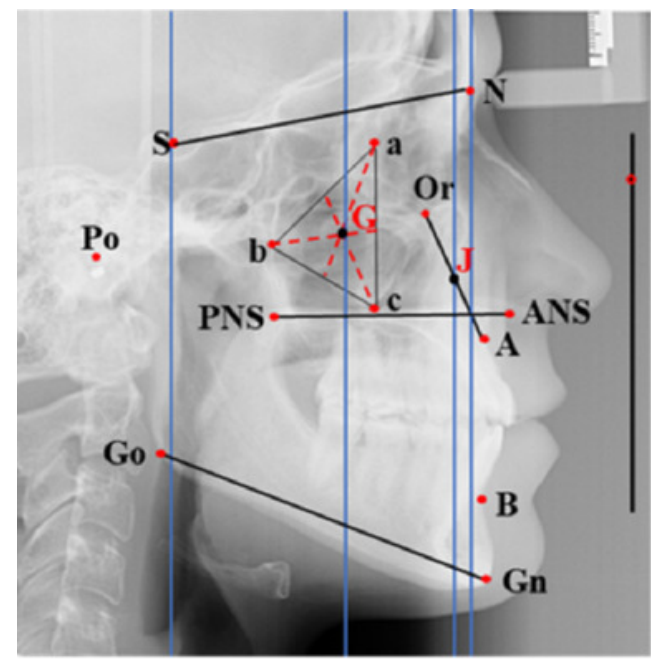

A

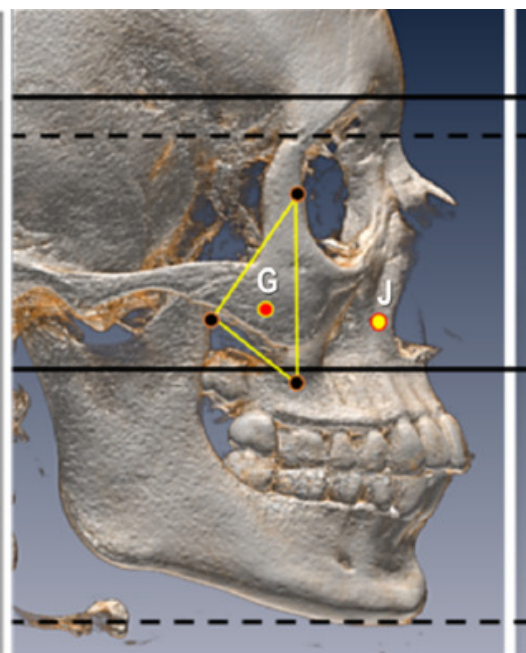

B

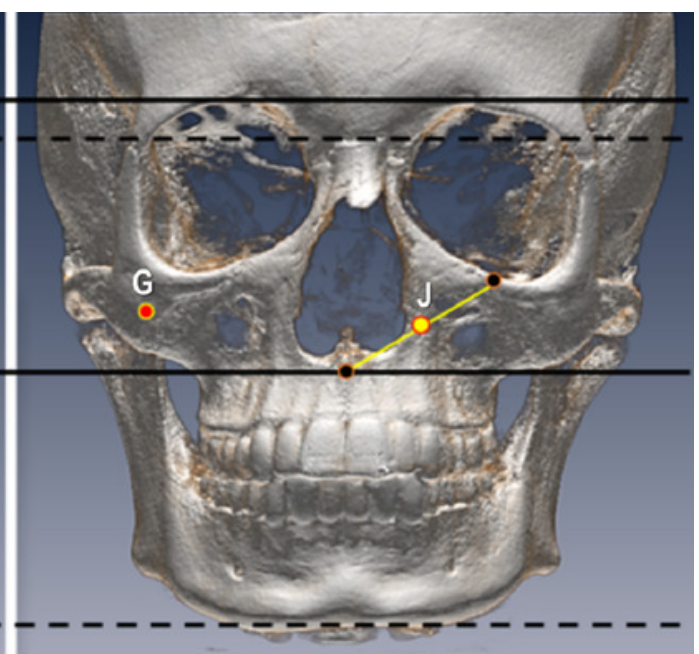

C 


\section{Figure 2}

Superimposed cephalometric and soft tissue facial profiles of adult patients

. Superimposed cephalometric and soft tissue facial profiles of adult patients exhibiting different midface positions based on measurements to geometric landmarks J and G, and reflecting the 4 different groups defined in the study. The ratios of NJ/SN and NG/SN are indicated with the corresponding interpretation: NJ/SN Group* Maxillary midface NG/SN Group* Zygomatic midface A $-7.7<0.73$ full $34.4<\mathbf{4 0 . 2 3}$ full B 1.97 within range $0.73-6.41$ normal toward full 43.7 within range 40.23 - 44.41 normal toward full C 7.17 within range 6.41 - 12.09 normal toward flat 43.8 within range 40.23 - 44.41 normal toward full D $18.5^{\text {> }}$ 12.09 flat $53.01>\mathbf{4 8 . 5 9}$ flat *as indicated in Table 1

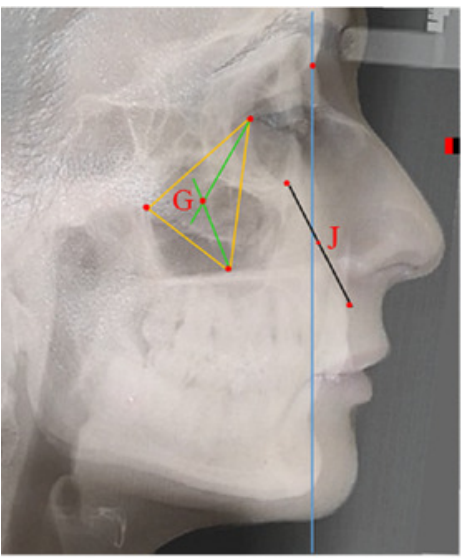

A

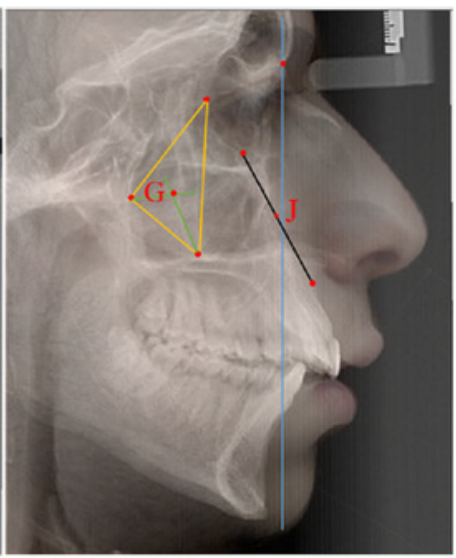

B

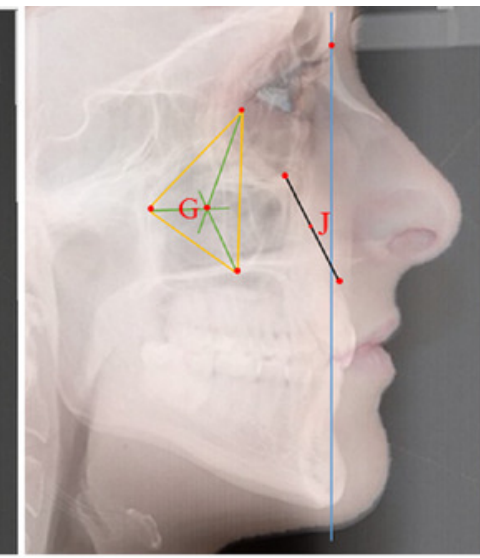

C

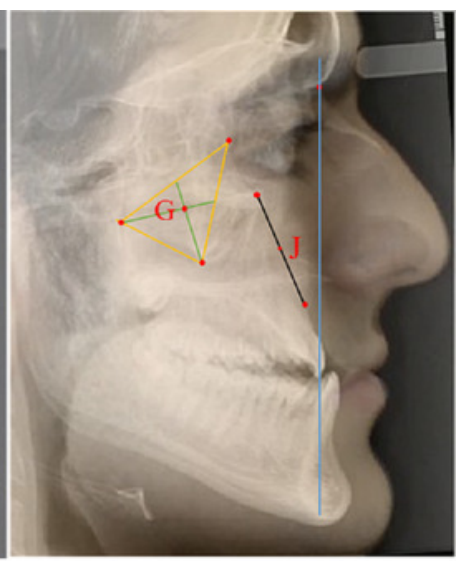

D 